LA-UR-01-3148

Approved for public release; distribution is unlimited.

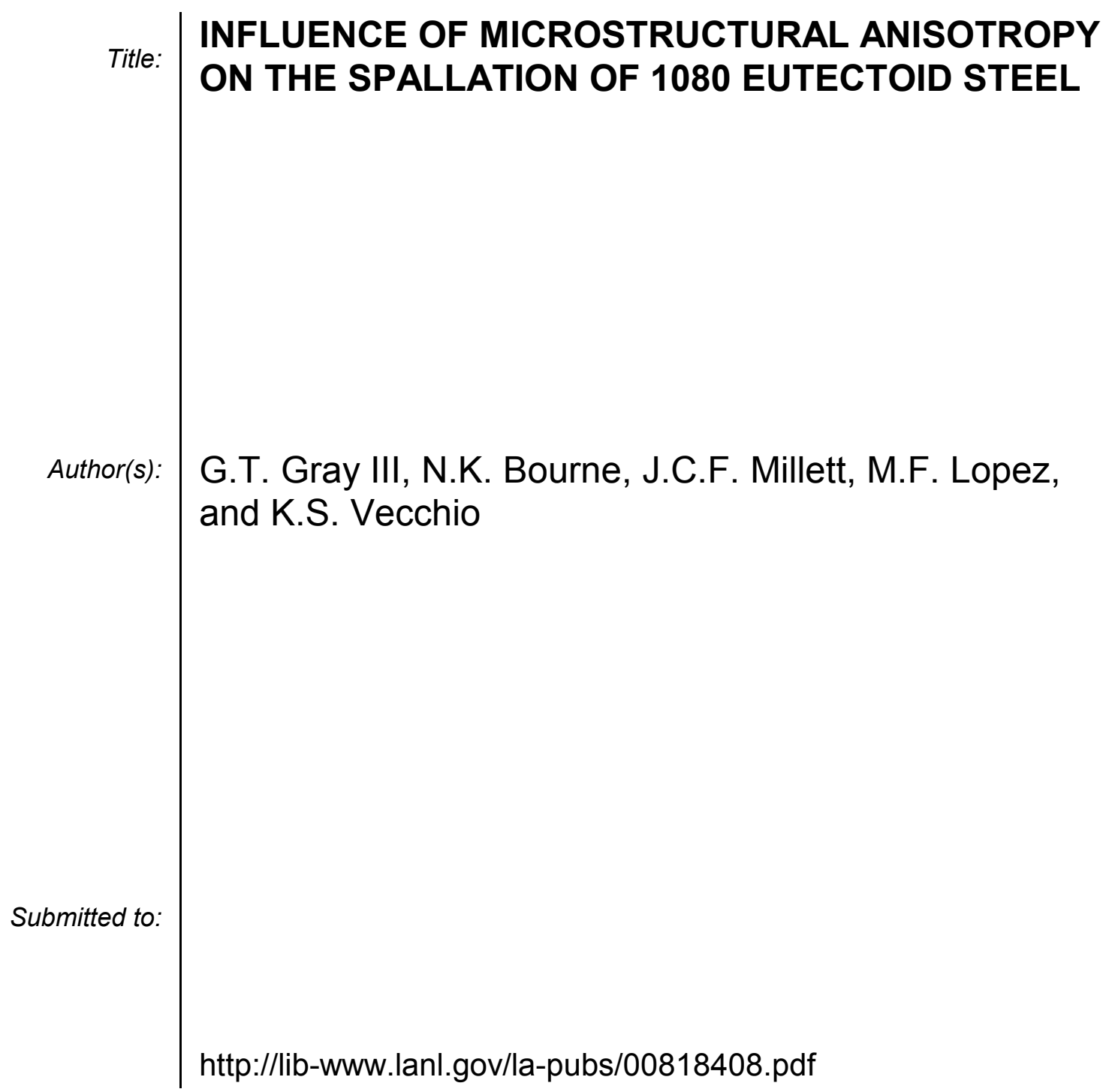

Los Alamos National Laboratory, an affirmative action/equal opportunity employer, is operated by the University of California for the U.S. Department of Energy under contract W-7405-ENG-36. By acceptance of this article, the publisher recognizes that the U.S. Government retains a nonexclusive, royaltyfree license to publish or reproduce the published form of this contribution, or to allow others to do so, for U.S. Government purposes. Los Alamos National Laboratory requests that the publisher identify this article as work performed under the auspices of the U.S. Department of Energy. Los Alamos National Laboratory strongly supports academic freedom and a researcher's right to publish; as an institution, however, the Laboratory does not endorse the viewpoint of a publication or guarantee its technical correctness. 


\title{
INFLUENCE OF MICROSTRUCTURAL ANISOTROPY ON THE SPALLATION OF 1080 EUTECTOID STEEL
}

\author{
G.T. Gray III, N.K. Bourne*, J.C.F. Millett*, M.F. Lopez, and K.S. Vecchio**: \\ Los Alamos National Laboratory, Los Alamos, NM 87545 \\ * Royal Military College of Science, Cranfield University, Shrivenham, Swindon, SN6 8LA, UK. \\ ** University of California-San Diego, MAE Department, La Jolla, CA 92093-0411
}

\begin{abstract}
While the influence of crystallographic texture on elastic and plastic constitutive response has seen extensive investigation in recent years, the influence of texture on the dynamic fracture of engineering materials remains less extensively explored. In particular, the influence of anisotropy, both textural and morphological, on the spallation behavior of materials remains poorly quantified. In this study, the spallation response of 1080-steel has been studied as a function of microstructural morphological anisotropy. In this study the influence of elongated $\mathrm{MnS}$ stringers, resident within a crystallographically isotropic eutectoid steel, on the spallation response of 1080 steel was investigated. That of a fully-pearlitic 1080 steel loaded to $5 \mathrm{GPa}$ was found to be dominated by the heterogeneous nucleation of damage normal and orthogonal to the MnS stringers. Delamination between the matrix pearlitic microstructure and the $\mathrm{MnS}$ stringers was seen to correlate to a significantly lower pull-back signal during transverse loading than to that parallel to the stringer axis. The "pull-back" signals and postspallation metallographic observations are discussed with reference to the influence of microstructural anisotropy on void nucleation and growth.
\end{abstract}

\section{INTRODUCTION}

While the influence of crystallographic texture on metal plasticity has seen in-depth study over the last 40 years (1), the role of anisotropy (due to texture or morphology) on fracture remains poorly understood $(2,3)$. The effects of anisotropy on fracture can be: 1) atomistic in nature on a single-crystal level, such as the role of crystallographic orientation on cleavage fracture $(4,2)$ microstructural anisotropy $(5,6)$ due to microscopic directionality (grain shape, etc.), 3) elastic and plastic anisotropy in damage initiation and growth in a polycrystal (7), or 4) macroscopic due to long-range microstructural constructs such as those in continuous or particulatereinforced composites, laminated composites, and/or functionally-graded materials.

Strong crystallographic texture in high-purity zirconium has been shown to lead to anisotropic damage evolution during tensile loading resulting in ellipsoidal-shaped ductile dimples following isotropic void nucleation $(3,8)$. Anisotropic damage evolution has been shown to control the quasi-static fracture response and ballistic impact resistance due to second-phase (elongated $\mathrm{MnS}$ stringers) initiation processes in HY-100 and armor steel, respectively $(5,6)$. Conversely, the "pull-back" signals in spalled $\mathrm{Zr}$ was found to be unaffected by strong crystallographic texture (3). This behavior was postulated to be due to isotropic damage evolution in the high-purity, albeit strongly crystallographically-textured $\mathrm{Zr}$ (3).

The development of predictive materials models in structural finite-element codes requires, in addition to its constitutive behavior, understanding of the dominant micromechanisms controlling damage evolution and fracture in a material and its linkage to microstructure and therefore material processing. The development of predictive damage-evolution and fracture models therefore requires a detailed understanding of the correlated effects between microstructure and anisotropy (crystallographic and 
microstructural) because many engineered materials possess directional mechanical properties.

The goal of this study was to quantify the influence of microstructural anisotropy, specifically anisotropically-oriented $\mathrm{MnS}$ stringers, within a crystallographically isotropic material on its damage evolution and spallation response. The material selected for this study was 1080 eutectoid rail steel.

\section{EXPERIMENTAL TECHNIQUES}

The material used for this investigation was a hotrolled rail steel manufactured by U.S. Steel and supplied by the Association of American Railroads (9). The analyzed chemical composition of this steel (wt. pct.) is: 0.80 carbon, 0.17 silicon, 0.84 manganese, 0.013 sulfur, and 0.018 phosphorus (conforming to AISI 1080 steel). The rail steel studied possesses a fully pearlitic microstructure with pronounced $\mathrm{MnS}$ stringers elongated along the rail axis formed during hot rolling. The crystallographic texture of the rail steel was measured using X-ray diffraction. The texture of the rail steel investigated was quantified to be nearly purely random in nature as reflected by the average texture value of 1.02 (10).

To examine the influence of loading orientation, and thereby microstructural anisotropy, on the constitutive and fracture response of the rail steel, compression and tensile samples, for both quasistatic, dynamic tensile and spallation testing, were sectioned from the longitudinal and transverse directions relative to the rail axis. The quasi-static and dynamic compressive stress-strain response was found previously to be isotropic, consistent with the nearly random texture of the rail steel (10). However contrary to the compressive properties, the anisotropic distribution and orientation of the $\mathrm{MnS}$ stringers was seen to lead to a pronounced difference in the strain-to-failure during tensile testing at quasi-static and dynamic loading rates. The transverse-oriented tensile samples displayed drastically reduced strains to failure compared to the longitudinal-oriented samples(10). The pronounced influence of this anisotropic damage evolution in 1080 steel on uniaxial fracture was the motivation for the current study.

To examine the influence of loading orientation on the spallation response of this strongly microstructurally-anisotropic eutectoid steel, $50 \mathrm{~mm}$ diameter by $6 \mathrm{~mm}$ thick samples were sectioned from the rail section. The wave speeds in the 1080 steel samples were measured to be: $\mathrm{C}_{\mathrm{L}}=5.95$ $\mathrm{km} / \mathrm{sec}$ and $\mathrm{C}_{\mathrm{S}}=3.26 \mathrm{~km} / \mathrm{sec}$. Plate impact experiments were carried out using a $50 \mathrm{~mm}$ bore gas gun. In all cases, the impactors were mild steel of thickness $3.0 \mathrm{~mm}$ and the 1080 targets were of thickness $6.0 \mathrm{~mm}$ so that a central spall plane was introduced. The samples were impacted at $208 \mathrm{~m} \mathrm{~s}^{-1}$ for a nominal shock pressure of $3 \mathrm{GPa}$. Longitudinal stress profiles were measured with commercial manganin stress gauges placed on the rear face of the specimens and supported with thick polymethylmethacrylate (PMMA) blocks. These gauges (Micromeasurements type LM-SS-125CH048) have been calibrated previously by Rosenberg (11). The impact velocity was measured to an accuracy of $0.5 \%$ using a sequential pin-shorting method and tilt was fixed to be less than $1 \mathrm{mrad}$ by means of an adjustable specimen mount. The mild steel impactor plates were mounted onto a polycarbonate sabot with a relieved front surface in order that the rear of the flyer plate remained unconfined. Targets were machined and lapped such that they were flat to less than $2 \mu \mathrm{m}$ across the surface. The spalled 1080 samples were "softrecovered" by decelerating the shocked samples in layers of rags. Specimens for optical metallography were sectioned from the shock-recovered samples and prepared for optical metallography as previosly described (10).

A shock profile test, using identical impact stresses, sample dimensions, and gauge configuration, was also conducted on the mild steel EN3 (12) for comparison with the 1080 steel tests. The EN3 material is a low carbon steel $(0.2 \mathrm{wt} . \% \mathrm{C}$ and 0.9 wt.\% $\mathrm{Mn}$ ) containing a mixed ferrite/pearlitic steel microstructure. Its longitudinal sound speed is $5.91 \mathrm{~km} / \mathrm{sec}$ and its shear wave speed is $3.25 \mathrm{~km} / \mathrm{sec}$.

\section{RESULTS AND DISCUSSION}

\section{Manganin-Gauge Data}

Preferred crystallographic or microstructural anisotropy in polycrystals can result in orientationdependent constitutive and damage properties (13) and can also affect damage evolution and fracture mechanisms $(2,10)$. The strong microstructural 
anisotropy, previously shown to produce such a dominant effect on the uniaxial-stress fracture behavior at low- and high-strain rates of 1080 steel (10), was found in this study to: a) have no influence on the shock "ring-up" and HEL of 1080 steel, while 2) significantly altering the overall magnitude of the spallation "pull-back" signal as a function of loading orientation (Fig. 1).

The gauge profiles during for both 1080 steel orientations are seen to display many essentiallyidentical features. The Hugoniot-elastic limits (HEL's) (noted as point A) in Fig. 1 are seen to be similar in both orientations. The HEL measured in the PMMA (seen at $0.33 \mathrm{GPa}$ in Fig. 1) converts to approximately $2 \mathrm{GPa}$ in the 1080 steel sample using the elastic wave speeds in the 1080 steel. This value is consistent with the yield strength of this steel at a strain rate of $1200 / \mathrm{sec}$ at room temperature is $c a$. 1 $\mathrm{GPa}$ after consideration of the stress state. Converting the uniaxial yield strength of $1 \mathrm{GPa}$ to a uniaxial strain state (by multiplying by $\frac{1-2 \gamma}{1-\gamma}$ ) yields

a predicted HEL of $c a .2 \mathrm{GPa}$. The details in the top portions of the profiles, where step-like features are seen, remain unexplained at the present time. The presence of these features is inconsistent with elastic-plastic releases due to the PMMA backing plate. Upon relaxation from the Hugoniot state the break in the wave profiles for both orientations(denoted as point "B" in Fig. 1) is also seen to be very reproducible and could suggest the elastic-plastic transition in the steel. The magnitude of this reverse elastic-plastic transition is however significantly lower than the HEL which could suggest that 1080 steel displays complex anelastic behavior during shock release (14).

The timing of the reverberation "ringing" in the spallation signal after the "pull-back" is consistent with the traditional trapping of momentum in the scab rear portion of the spalled sample following the generation of a "free-surface" (although complete separation of neither target occurred at this stress level; i.e the spall was incipient). The "pull-back" signals for the two spalled 1080 samples (as denoted by point " $C$ " in Figure 1) are seen to exhibit different magnitudes; the longitudinal orientation displaying a larger "pull-back". The magnitude of this signal reflects the amount of energy necessary to induce spallation in the target. The larger value for the longitudinal oriented sample is consistent with the significantly higher fracture strains displayed by the longitudinal rather than the transverse orientation (10). This observation is thought to reflect the anisotropic local damage initiation due to the elongated MnS stringers present in this steel which is crystallographically isotropic in the bulk. This finding is further consistent with the results of Leach (5) who reported a strong relationship between inclusion orientation and shearband formation during ballistic impact.

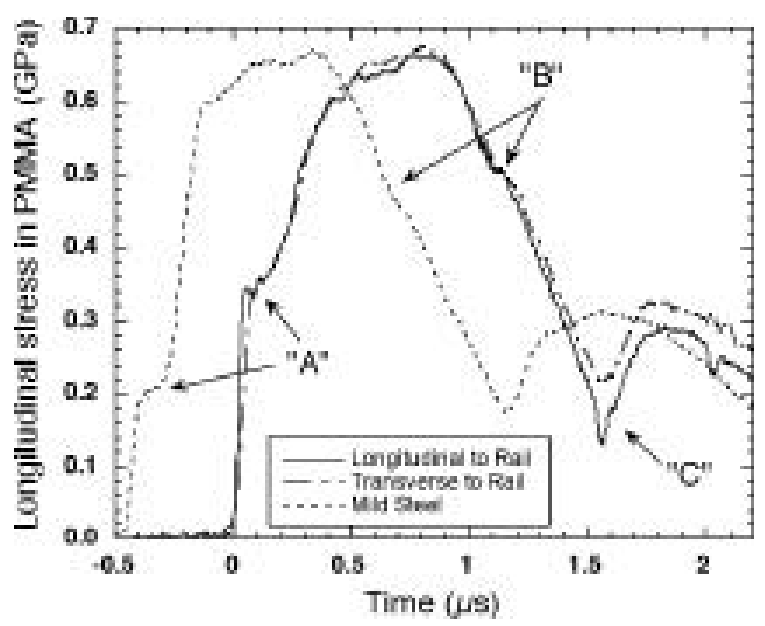

FIGURE 1. Gauge trace for 1080 eutectoid steel spalled in the longitudinal and transverse directions relative to the rail axis.

\section{Damage Evolution}

The damage evolution in 1080 steel as a function of loading orientation was evaluated through metallographic examination of the "soft-recovered" and spalled samples. Figure 2 shows the damage evolved in the incipiently spalled 1080 steel samples as a function of loading orientation. The primary damage mode observed in both the longitudinal and transverse samples was seen to be extensive microcracking and decohesion along the $\mathrm{MnS}$ inclusions and small ( 10 micron) nominally spherical-shaped ductile voids associated with the ends of the stringers. Damage in the transverse orientation is seen to entail cracking along the MnS stringers and between the stringers. Damage in the longitudinally oriented sample is seen to display void formation adjacent to stringers as well as outof-spall plane decohesion along the stringers. This decohesion normal to the plane of maximum stress in the spall is consistent with the hydrostatic tensile loading stress of spallation (uniaxial strain state) and the low interfacial strength of the $\mathrm{MnS}$ with the steel matrix. 


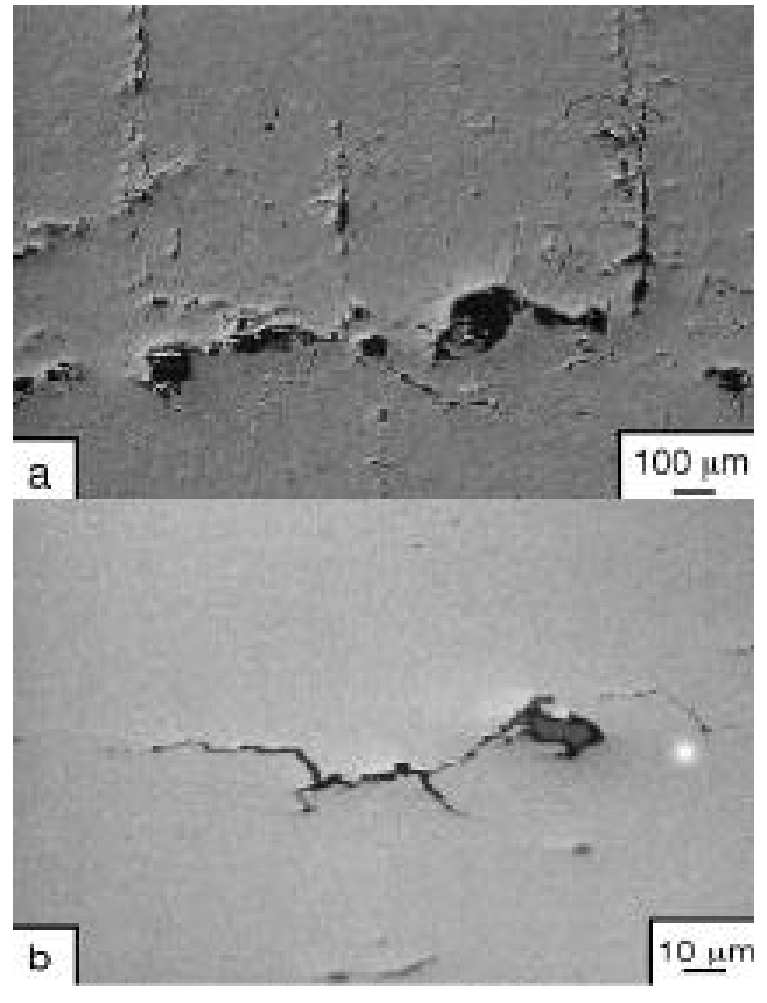

FIGURE 2. Comparison of the damage evolution in recovered spalled samples for the: a) longitudinal, and b) transverse loading directions for 1080 steel.

\section{SUMMARY AND CONCLUSIONS}

The effect of microstructural anisotropy on the spallation behavior of 1080 eutectoid steel was studied using manganin gauge measurements and post-mortem analysis of the "soft" recovered and spalled samples. The response of a fully-pearlitic 1080 steel loaded to $5 \mathrm{GPa}$ was found to be dominated by the heterogeneous nucleation of damage normal and orthogonal to the $\mathrm{MnS}$ stringers. Delamination between the matrix pearlitic microstructure and the $\mathrm{MnS}$ stringers was seen to correlate to a significantly lower reload signal during transverse loading than loading parallel to the stringer axis. The "pull-back" signals and postspallation metallographic observations are discussed with reference to the influence of microstructural anisotropy on void nucleation and growth.

\section{ACKNOWLEDGMENTS}

This work was supported under the auspices of the United States Department of Energy.

\section{REFERENCES}

1. Maudlin, P.J., Gray_III, G.T., Cady, C.M., and Kaschner, G.C., Philos. Trans. Roy. Soc. A, 357, 17071729 (1999).

2. Sevillano, J.G. and Meizoso, A.M., "The Influence of Texture on Fracture," in 8th Int. Conf. on Textures of Materials (ICOTOM 8), edited by J.S. Kallend and G. Gottstein, The Metallurgical Society, 1988, pp. 897911.

3. Gray III, G.T., Bourne, N.K., Zocher, M.A., Maudlin, P.J., and Millett, J.C.F., "Influence of Crystallographic Anisotropy on the Hopkinson Fracture "Spallation" of Zirconium," in Shock Compression of Condensed Matter - 1999, edited by M.D. Furnish, L.C.

Chhabildas, and R.S. Hixson, American Institute of Physics, New York, 2000, pp. 509-512.

4. Bowen, A.W., Acta Metall., 26, 1423-1433 (1978).

5. Leach, P.W. and Woodward, R.L., J. Mater. Sci., 20, 854-858 (1985).

6. Goto, D.M., Koss, D.A., and Jablokov, V., Metall. \& Matls. Trans., 30A, 2835-2842 (1999).

7. Chan, K.S. and Koss, D.A., Metall. \& Matls. Trans., 14, 1333-1342 (1983).

8. Kaschner, G.C. and Gray III, G.T., Metall. \& Matls. Trans., in press (2000).

9. Gray III, G.T., Williams, J.C., and Thompson, A.W., Metall. Trans., 14A, 421-433 (1983).

10. Gray III, G.T., Vecchio, K.S., and Lopez, M.F., "Influence of Microstructural Anisotropy on the Quasi-static ad Dynamic Fracture of 1080 Eutectoid Steel," in Fundamental Issues and Applications of Shock-Wave and High-Strain-Rate Phenomena, edited by K.P. Staudhammer, L.E. Murr, and M.A. Meyers, Elsevier Science Ltd, New York, 2001, pp. 157-163.

11. Rosenberg, Z., Yaziv, D., and Partom, Y., J. Appl. Phys., 51, 3702-3705 (1980).

12. Millett, J.C.F., Bourne, N.K., and Rosenberg, Z., J. Appl. Phys., 81, 2579-2583 (1997).

13. Maudlin, P.J., Bingert, J.F., House, J.W., and Chen, S.R., Int. J. Plast. 2 15, 139-166 (1999).

14. Johnson, J.N., Hixson, R.S., Gray, G.T., and Morris, C.E., J. Appl. Phys., 72, 429-441 (1992). 